\title{
Question-led approach in designing Dijkstra algorithm game- based learning: A pilot study
}

\author{
Rosni Ramle' ${ }^{1}$, D'oria Islamiah Rosli ${ }^{2}$, Shelena Soosay Nathan ${ }^{3}$, Mazniha Berahim ${ }^{4}$ \\ ${ }^{1,3,4}$ Department of Information Technology, Universiti Tun Hussein Onn Malaysia, Malaysia \\ ${ }^{2}$ Department of Professional Education, Universiti Tun Hussein Onn Malaysia, Malaysia
}

\section{Article Info \\ Article history: \\ Received Apr 7, 2020 \\ Revised Sep 18, 2020 \\ Accepted Oct 21, 2020 \\ Keywords: \\ Data structure \\ Game-based learning \\ Question prompt \\ Question-led learning \\ Socratic method}

\begin{abstract}
Dijkstra algorithm is important to be understood because of its many uses. However, understanding it is challenging. Various methods to teach and learn had been researched, with mixed results. The study proposes questionled approach of the algorithm in a game-based learning context. The game designed based on an existing game model, developed and tested by students. Pre- and post-game tests compared and game feedback survey analysed. Results showed that students' performance in graph data structure Dijkstra algorithm improved after playing the game where post-test mark was higher than pre-test. Game feedback were mostly positive, with areas of improvement. Students may use the game as a learning tool for self-regulated learning. Educators may get some ideas on how to design teaching tool using question-led approach.
\end{abstract}

This is an open access article under the CC BY-SA license.

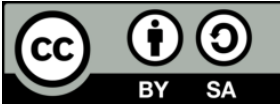

\section{Corresponding Author:}

Rosni Binti Ramle,

Department of Information Technology,

Universiti Tun Hussein Onn Malaysia,

KM 1, Jalan Panchor, 84000, Muar, Johor, Malaysia.

Email: rosni@uthm.edu.my

\section{INTRODUCTION}

Network Optimization Problems (NOP) can be better analyzed by graph [1]. Shortest Path Problem (SPP) is one of NOP where its solution mostly used Dijkstra's algorithm [1] to find minimum distance between two vertices [2]. The algorithm commonly used in manufacturing, computer networks, transport, and telecommunications, making it a crucial topic to be understood by students.

However, teaching [3,4] and learning [5] the algorithm can be difficult. These were experienced and can be seen by two of the authors when teaching the algorithm to first-year Diploma in Information Technology students. Futhermore, understanding technical terms requires hands-on practice rather than conventional learning [6]. Thus, researchers came up with various methods to simplify understanding of the algorithm. Sowell, et al. [7] implemented active learning where students did exercises in groups in class then presented their solutions to be commented by their instructor and classmates. Chen, et al. [8] applied kinesthetic learning activities (KLA) by role-playing whereby a weighted graph is represented by students and items. Hundhausen [9] gave algorithm visualisation (AV) construction and presentation assignments where students were asked to choose an example, design and present the storyboard and the resulting animation. Seraj and Chui [6] developed a Flash-based mobile learning prototype. Researchers [1, 4, 10-15] created AV softwares which can be used locally and/or via the Web. From the methods applied, it can be seen that not all used technology. And for those that did, the digital learning tool is either created by the educators or students, mobile or PC-based, accessed locally and/or web-based. 
Unfortunately, efforts to simplify learning unable to optimally engage learners [16]. With the current resources, educators should use different approaches to learning [17]. Silva, et al. [18] suggested game-based learning (GBL) to make learning fun. Chang, et al. [19] created a board game called Ticket to Ride where students chose missions that require connecting one city to another. El-Sheikh and Prayaga [20] asked students to develop educational algorithms' games, among them is the application of Dijkstra's algorithm in navigating through a terrain and finding a shortest path to reach a destination. Graven, et al. [21] requested students to play a short computer game where the world is a network modelled as a labyrinth. Grivokostopoulou, et al. [22] made a game to teach search algorithms, based on the Pacman game. Notice that the games can either be non-digital or digital, and developed by either educators or students.

Although visualizations employed in games, they are in most cases not interactive [18]. This paper proposed combining GBL with question-led approach, a method which uses questions to lead students through the process of solving problems [23], to design gameplay that results in meaningful learning. Use of questions in learning process proven better than conventional teaching [24] as it motivates thinking and learning [25], enhance focus and enable reflection of learning processes [26], support problem-solving [27], effective in knowledge integration [28] and increase self-regulated learning competence [29]. The approach utilized in different contexts such as economy [24], mathematics [23] and physics [30].

\section{RESEARCH METHOD}

Figure 1 shows a model by Garris [31] used to design the game. Instructional content combined with game characteristics results in a game cycle of user judgement and behaviour and system feedback. Achievement of learning outcome concluded after debriefing.

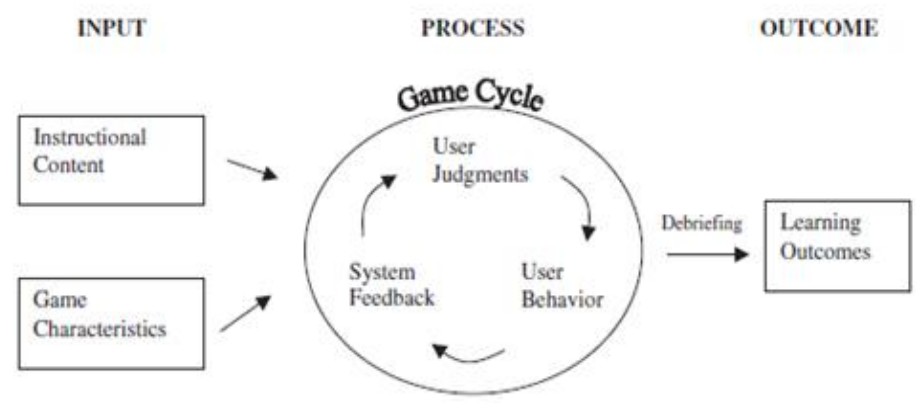

Figure 1. Input-process-outcome game model [31]

Adobe Flash integrated multimedia elements. Player can study Notes before play. Game contact, graphics, sound, time, life, score and screen are game characteristics involved. Mouse used to interact with game. 2D graphics created/edited using Adobe Photoshop. Zombie apocalypse theme background audio continuously play and certain events trigger sound effects e.g. button click, correctness of answer (true/false), and result (won/lost). Player (as a scientist) needs to find the shortest path to a research facility using Dijkstra algorithm to give the antidotes to a zombie virus. Time, Life and Score located top-middle of screen show time left, lives left and score attained during game. Each wrong answer decreases Life whereas each correct answer increases Score. If mission finishes within given time and lives, player wins. Game screens are Title to display game title, Menu that provide options of game application, Demo to give game tutorial, Story overview to walkthrough background story of game, Play to play the game, Won to inform game completion, Lost to inform game is over, Exit to ask player confirmation to quit game and Credits to display information of game designers and developers.

Given a graph and a source vertex in the graph, Dijkstra algorithm can find shortest path from source to all vertices in the given graph. Algorithm to find shortest distance is as follows [32]:

Set distance of start vertex from start vertex $=0$

Set distance of all other vertices from start $=\infty$

Repeat until all vertices visited

Visit unvisited vertex with smallest known distance from start vertex

For each unvisited neighbour of current vertex

Calculate distance from start vertex

If calculated distance of a vertex is less than known distance then

Question-led approach in designing Dijkstra algorithm game-based learning: A pilot study (Rosni Ramle) 
Update shortest distance

Add current vertex to list of visited vertices

Update previous vertex for each of the updated distances

In the game, Dijkstra algorithm presented as a series of multiple-choice questions from start to end. Player answers questions based on a map and a table (Figure 2), inspired by [33].

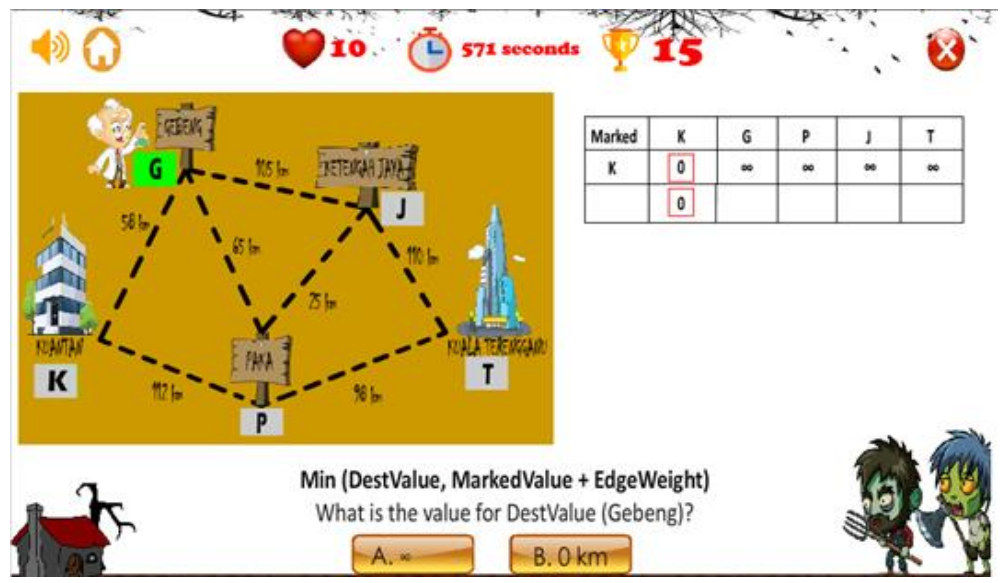

Figure 2. Play screen

The following shows the series of questions (in bold) asked during play based on the above algorithm:

What is the value in column source_vertex?

Update source vertex column in row 1 to 0

What is the value in the remaining columns (unexplored vertices)?

Update remaining columns in row 1 to $\infty$

Repeat until all vertices visited (number of rows $=$ number of vertices in graph)

What is the smallest unmarked value in the row_number row?

Mark column that has the smallest unmarked value (Figure 2)

Copy marked value in new row (Figure 2)

Find unvisited neighbour(s) of current_vertex

For each unvisited vertex

Is there an edge that directly connects current_vertex and unvisited_vertex?

If yes

What is the value for DestValue?

What is the value for MarkedValue?

What is the value for EdgeValue?

What is the min value in column unvisited_vertex?

If current min value < previous min value

Update column unvisited_vertex to current min value

Else

End if

Retain column unvisited_vertex to previous min value

Else

End if

Retain column unvisited_vertex to previous row

End for

End repeat

To find shortest path from the filled table, backtrack from the final vertex. The algorithm is as follows:

Int. J. Eval. \& Res. Educ. Vol. 9, No. 4, December 2020: 926 - 933 
Tick destination vertex

Repeat until all rows visited

Move upwards

If there is a change in value then

Tick vertex that was marked in that row

Move pointer to point to marked vertex's column algorithm.

The following shows the series of questions (in bold) asked during play based on the above

Tick destination_vertex

Repeat until all rows visited

Move pointer one row upward

Has the value changed?

If yes

Tick vertex that was marked in that row

Move pointer to point to marked vertex's column

End if

End repeat

In process phase of the game model, user judgements made during information gathering, reasoning, and decision making before each question answered. User behaviour is the clicking of an answer. The correctness of an answer triggers system feedback in the form of audio (negative/positive), Life (stay/decrease), Score (stay/increase), and screen displayed (Play/Won/Lost). The cycle repeats as system feedback will then affect the next user judgement. During debriefing, user will reflect the gameplay and determine whether the learning outcomes of the game achieved, which is to understand the Dijkstra algorithm (cognitive), solve SPP using Dijkstra algorithm on paper using a table (psychomotor) and appreciate the worth of the Dijkstra algorithm in solving real life problems (affective). The series of questions simulate the question thinking process that a student should undergo to solve SPP using Dijkstra algorithm. As game can be repetitively played, students able to remember and understand the problem-solving process and formulate the right sequence of questions when solving problems of similar nature.

The research employed a quasi-experimental design using a pre-test post-test only design without a control group. The game was pilot-tested by 28 first-year Diploma in Information Technology students who learnt the algorithm the previous semester, during class time, close to one hour, individually. Players answered a pre-game test, played the game, answered a post-game test and filled out a game feedback survey. Pre- and post-game tests consist of the same questions on Dijkstra algorithm whereby players need to complete an empty table based on a given graph. The game was uploaded in the class's Whatsapp group with .swf file format. Students downloaded the game and opened them with Flash Player or Internet Explorer. Game feedback survey modified from [34] consists of nine Likert-scale questions ranging from strongly agree to strongly disagree and two open-ended questions on favourable traits of game and suggestion for improvement.

There were many reasons for the small sample size. First, only one of the authors was available to handle testing. This lack of manpower caused the inability to conduct testing to different groups of students. Second, testing had to be done during weekday as classroom usage is prohibited during weekend. Because both the testing coordinator and the students had classes, the time constraint made it difficult to find a time slot where both were free. Third, finding a venue for the testing during weekday was a challenge since most classrooms were occupied most of the time. Location constraint means that even if both the testing coordinator and the students were free, an empty classroom is not necessarily available. Fourth, the maximum capacity of a classroom is 30 . A sample size of more than that requires the testing coordinator to conduct testing to more than one group of students, which was not possible at the time.

Given the constraints mentioned above, a convenience sampling was done where the students who participated in the testing was a section that the testing coordinator was teaching during that time. The authors are aware that a sample size insufficiency may threat the validity and generalizability of the study's results. However, a small sample size is common in education research's pilot studies. Chen and Yao [35] did an empirical evaluation of critical factors influencing learning satisafaction in a blended learning of 20 students. Flack, et al. [36] leveraged serious games in Air Force Multi-Domain Operations education to five soldiers. Dawson and Sutherland-Smith [37] paid seven experienced markers individually blind marked the same bundle of 20 second-year psychology assignments to establish their accuracy at detecting contract cheating. Aspelin and Jonsson [38] studied relational competence in teacher education which focuses on

Question-led approach in designing Dijkstra algorithm game-based learning: A pilot study (Rosni Ramle) 
interpersonal aspects of six preservice teachers. Beltrán-Velasco, et al. [39] explored the effect of differences in the stress psychophysiological response of 25 Psychology degree students. Baker, et al. [40] assessed patterns of cortical activity that occur when 10 children interact with digital math apps.

Gender, age, and knowledge on Dijkstra algorithm may be the confounding variables in the study. Restriction eliminates variation in the confounder [41]. Thus, why the samples were those of same age. However, restriction lowers generalizability [42]. Hence, the differing genders and knowledge of Dijkstra algorithm of the samples.

\section{RESULTS AND DISCUSSION}

Table 1 illustrates summarization of results from pre-game and post-game experiment. All but one cell in table accomplished positive change i.e. post-test mark is higher than pre-test. To extract feedback on game, we asked the players to answer nine five-point Likert scale questions ranging from strongly disagree to strongly agree. The results are summarized in Table 2 .

Table 1. Comparison between pre-game and post-game test

\begin{tabular}{cccc}
\hline & \multicolumn{3}{c}{ Result } \\
Question & Pre & $\begin{array}{c}\text { Post } \\
\text { Correct }\end{array}$ & Change \\
\hline R1C1 & 24 & 23 & - \\
R1C2 & 23 & 27 & + \\
R1C3 & 14 & 26 & + \\
R1C4 & 18 & 27 & + \\
R2C1 & 23 & 24 & + \\
R2C2 & 19 & 22 & + \\
R2C3 & 16 & 22 & + \\
R2C4 & 11 & 19 & + \\
R3C1 & 24 & 25 & + \\
R3C2 & 15 & 20 & + \\
R3C3 & 11 & 18 & + \\
R3C4 & 2 & 6 & + \\
\hline R $=$ Row and C Column
\end{tabular}

$\mathrm{R}=$ Row and $\mathrm{C}=$ Column

Table 2. Game feedback

\begin{tabular}{cccccc}
\hline Criteria & $\begin{array}{c}\text { Strongly } \\
\text { Disagree }(\%)\end{array}$ & Disagree (\%) & Neutral (\%) & Agree (\%) & $\begin{array}{c}\text { Strongly } \\
\text { Agree }(\%)\end{array}$ \\
\hline Training and help & 0 & 0 & 21.43 & 42.86 & 35.71 \\
Effectiveness & 0 & 0 & 10.71 & 67.86 & 21.43 \\
Usability & 0 & 7.14 & 3.57 & 64.29 & 25.00 \\
Gameplay (Challenge) & 0 & 10.71 & 39.29 & 42.86 & 7.14 \\
Motivation (Feedback) & 0 & 3.57 & 21.43 & 46.43 & 28.57 \\
Motivation (Attention) & 0 & 7.14 & 10.71 & 39.29 & 42.86 \\
Motivation (Curiosity) & 0 & 3.57 & 14.29 & 50.00 & 32.14 \\
Pleasure/fun & 0 & 3.57 & 10.71 & 39.29 & 46.43 \\
Gameplay (Navigation) & 0 & 7.14 & 28.57 & 39.29 & 25.00 \\
Average (\%) & 0.00 & 4.76 & 17.86 & 48.02 & 29.37 \\
\hline
\end{tabular}

Players' opinion was mostly positive for all questions. This is reflected in many of the players' answer when asked to describe what they like about the game. They stated that the game made it "easy to understand the technique to find shortest path," therefore "improve knowledge" and "educate" on Dijkstra algorithm. This agrees with the result from the study by [43], where students felt that educational game clarifies data structure concepts. This may be because the notes given are "detailed" but "easy to understand," thus "help to play the game." Players can also use the game to "train" as they can repetitively play to "improve thinking skill." Feedback in the form of time, score and life made the GBL more "fun", "challenging" and "motivate" players to "not easily give up." A player "like" the zombie apocalypse theme of the game which influences the horror/thriller background sound that many players like as it is "like a scary film" and dark-coloured graphics, which a player like. Two players concluded the game to be "very special" and "perfect."

Players also suggested improvements in various aspects of the game. Students requested for the notes to be simpler as it "gives me anxiety feels like I'm reading slides. I feel like I'm preparing for test when actually I am getting ready to play the game." Because Dijkstra algorithm has many steps, we want the 
students to really understand each one, thus results in a lengthy explanation as each step is visualized and explained. As the game requires the players to analyse a map and a table to answer questions, it can be a bit overwhelming and confusing. To increase usability, students recommended to "give more instruction when playing," "teach more specifically," and "make the game more user friendly." Provide simple and easy instruction to make the beginner easy to play. An instruction manual [44] can be made to help players navigate and understand the game.

To increase the challenge, they proposed to "increase the difficulty level of the game," to improve learning outcomes [45]. This can be done by decreasing Time and Lives, increasing number of vertices, and put more than one smallest unmarked value in a row i.e. more than one shortest path. However, some students asked to create "levels to make the beginner easy to play." Students wanted the game to "keep the previous score. So, I can try beat the score in the next game." Students proposed to "increase the time," eventhough we felt that the time given is adequate, and to fix timer error as "time speeds up when replay".

Students wished for "the reason for every right answer." Currently, the feedback for each right answer is an increase in score and a "positive" sound. Explaining each right answer, in our opinion, would clutter the screen and lengthen the playing time, which may cause disengagement [46]. In tems of graphics, students advised for it to be more "realistic," "fun," and "colorful." We think a dark color theme for the game is suitable as it has a zombie apocalypse theme. They also desired for the sound to be "more dramatic." To keep up with the zombie theme, we use a limited combination of horror and thriller audios, to not distract players from their task.

None of the players gave any negative comment or suggestion regarding curiosity, fun, and navigation criteria. Thus, we are unable to comprehend why some of them "disagree". Nevertheless, we will make assumptions regarding the results of these three criteria. The game lack mystery as it is simple and direct, thus may not induce much curiosity as to what happens next. But a player remarked that the game "totally enhances me curiosity." Balancing between fun and learning is tricky. We might have focus more on the learning part, resulting in the game being less fun, which is a common problem in GBL for programming [47]. Though a player commented that the game is "fun enough". Regarding navigation, we assume that players who "disagree" did so because of the timer error which causes the timer to be faster when replay, eventhough this is not related to navigation. We think that the "UI is easy to navigate," as mentioned by a player.

\section{CONCLUSION}

This research integrated two approach that are considered important in 21 st century education; question-led learning and game-based learning. Our approach leads students through the process of problem solving where questions plays an important part in the learning process. Questions are formulated based on existing algorithm. The research also presents findings on the implementation of a question-led approach in designing graph data structure Dijkstra algorithm GBL. Comparison between pre-game and post-game tests as well as analysis of game feedback was conducted. The findings showed that students' overall performance after using the game is better than before. Game feedbacks were mostly positive. However, improvements need to be made in terms of simplicity of Notes, clarity of instructions, level of challenge, score-keeping, feedback, user interface, and sound.

Students can use the game to practice and learn until they can self-ask while thinking when solving similar problems. Proficiency of the algorithm will positively impact students' academic performance and consequently, career prospects. Educators can use the proposed method to design learning tool that ease understanding of an algorithmic problem-solving process. Future work requires a gameplay design that can balance fun and learning, and better research design to increase generalizability of testing results.

\section{ACKNOWLEDGEMENTS}

This research is supported by Tier 1 grant H117 from UTHM's Research Management Centre.

\section{REFERENCES}

[1] W. da Silva Lourenço, et al., "TASNOP: A tool for teaching algorithms to solve network optimization problems," Computer Applications in Engineering Education, vol. 26, no. 1, pp. 101-110, 2017.

[2] B. Upadhyaya, Data Structures and Algorithms with Scala: A Practitioner's Approach with Emphasis on Functional Programming. Cham: Springer Nature Switzerland AG, 2019.

[3] F. Melo, B. Barros and A. Moraes, "Educational objects with Geogebra for aid to pedagogical practices in engineering," in 15th Brazilian Congress on Engineering Education, Belém, pp. 1-12, 1997. 
[4] I. Makohon, D. T. Nguyen, M. Sosonkina, Y. Shen and M. Ng, "Java Based Visulaization and Animation for Teaching the Dijkstra Shortest Path Algorithm in Transportation Networks," International Journal of Software Engineering \& Applications, vol. 7, no. 3, pp. 11-25, 2016.

[5] A. Drigas, et al., "A web based elearning and e-psychology modular environment," Proceedings of International Conference on Next Generation Web Services Practices, pp. 168-174, 2006.

[6] M. Seraj and Y. Chui, "A Study of User Interface Design Principles and Requirements for Developing a Mobile Learning Prototype", in 2012 International Conference on Computer \& Information Science, Kuala Lumpur, pp. 1014-1019, 2012.

[7] R. Sowell, Y. Chen, J. Buhler, S. Goldman, C. Grimm and K. Goldman, "Experiences with Active Learning in CS 3," Journal of Computing Sciences in Colleges, vol. 25, no. 5, pp. 173-179, 2010.

[8] P. Chen, P. Chiou, and G. Young, "A Study of Learning Effectiveness on the Dijkstra's Algorithm Modeled in an Interactive KLA Approach," in The 13th Int'l Conf on Frontiers in Education: Computer Science and Computer Engineering, Las Vegas, pp. 234-238, 2017.

[9] C. Hundhausen, "Integrating algorithm visualization technology into an undergraduate algorithms course: ethnographic studies of a social constructivist approach," Computers \& Education, vol. 39, no. 3, pp. 237-260, 2002.

[10] P. Karagiannis, I. Markelis, K. Paparrizos, N. Samaras and A. Sifaleras, "E-learning technologies: employing Matlab web server to facilitate the education of mathematical programming," International Journal of Mathematical Education in Science and Technology, vol. 37, no. 7, pp. 765-782, 2006.

[11] M. Sánchez-Torrubia, et al., "PathFinder: A Visualization eMathTeacher for Actively Learning Dijkstra's Algorithm," Electronic Notes in Theoretical Computer Science, vol. 224, pp. 151-158, Jan. 2009.

[12] A. Geschke, U. Kortenkamp, B. Lutz-Westphal and D. Materlik, "Visage - Visualization of algorithms in discrete mathematics," Zentralblatt für Didaktik der Mathematik, vol. 37, no. 5, pp. 395-401, 2005.

[13] T. Baloukas, "JAVENGA: JAva-based Visualization Environment for Network and Graph Algorithms," Computer Applications in Engineering Education, vol. 20, no. 2, pp. 255-268, 2009.

[14] I. Karas and S. Demir, "Dijkstra algorithm interactive training software development for network analysis applications in GIS," Energy Education Science and Technology Part A: Energy Science and Research, vol. 28, no. 1, pp. 445-452, 2011.

[15] A. Dapena, F. Vázquez-Araujo, P. Castro and M. Souto-Salorio, "A framework to learn graph theory using simple wireless network models," Computer Applications in Engineering Education, vol. 24, no. 6, pp. 843-852, 2016.

[16] A. Yohannis and Y. Prabowo, "Sort Attack: Visualization and Gamification of Sorting Algorithm Learning," in 7th International Conference on Games and Virtual Worlds for Serious Applications (VS-Games), pp. 1-8, 2015.

[17] A. Silva, D. Martins and I. Nigro, "Computer labs in the teaching of production engineering," INGEPROInnovation, Management and Production, vol. 2, no. 12, pp. 23-29, 2010.

[18] S. Shabanah, J. Chen, H. Wechsler, D. Carr and E. Wegman, "Designing computer games to teach algorithms," in Seventh International Conference on Information Technology, Las Vegas, pp. 1119-1126, 2010.

[19] W. Chang, T. Wang and Y. Chiu, "Board Game Supporting Learning Prim's Algorithm and Dijkstra's Algorithm," International Journal of Multimedia Data Engineering and Management, vol. 1, no. 4, pp. 16-30, 2010.

[20] E. El-Sheikh and L. Prayaga, "Development and Use of AI and Game Applications in Undergraduate Computer Science Courses," Journal of Computing Sciences in Colleges, vol. 27, no. 2, pp. 114-122, 2011.

[21] O. Graven, H. Hansen and L. MacKinnon, "A Blended Learning Exercise using a Computer Game based on Abstract Learning Materials," in ICL2009 Interactive Computer Aided Learning, Villach, 2009.

[22] F. Grivokostopoulou, I. Perikos and I. Hatzilygeroudis, "An Educational Game for Teaching Search Algorithms," in 8th International Conference on Computer Supported Education, Rome, pp. 129-136, 2016.

[23] V. Soancatl, A. León, C. Martínez and L. Torres, "Leading Students to Solve Maths Problems Using Question-led Learning," in 4th European Conference on Games Based Learning, Copenhagen, pp. 368-374, 2010.

[24] R. McCain, "Developing an On-Line Textbook: Question-Led Teaching and the World Wide Web," The Journal of Economic Education, vol. 30, no. 3, pp. 210-220, 1999.

[25] M. Adams, "The Practical Primacy of Questions in Action Learning," in Action Learning and Its Applications, Present and Future, 1st ed. Y. Boshyk and L. Dilworth, Ed. Palgrave Macmillan UK, pp. 119-130, 2010.

[26] X. Ge and S. M. Land, "Scaffolding students' problem-solving processes in an ill-structured task using question prompts and peer interactions," ETR\&D, vol. 51, no. 1, pp. 21-38, 2003.

[27] I. Choi, S. Land and A. Turgeon, "Instructor modeling and online question prompts for supporting peer-questioning during online discussion," Journal of Educational Technology Systems, vol. 36, no. 3, pp. 255-275, 2008.

[28] E. Davis, "Scaffolding students' knowledge integration: Prompts for reflection in KIE," International Journal of Science Education, vol. 22, no. 8, pp. 819-837, 2000.

[29] G. van den Boom, et al., "Reflection prompts and tutor feedback in a web-based learning environment: Effects on students' self-regulated learning competence," Computers in Human Behavior, vol. 20, no. 4, pp. 551-567, 2004.

[30] V. Law and C.-H. Chen, "Promoting science learning in game-based learning with question prompts and feedback," Computers \& Education, vol. 103, pp. 134-143, Dec. 2016.

[31] R. Garris, R. Ahlers and J. E. Driskell, "Games, motivation, and learning: A research and practice model," Simulation \& Gaming, vol. 33, no. 4, pp. 441-467, 2002.

[32] K. Drumm, Graph Data Structure 4. Dijkstra's Shortest Path Algorithm, 2016.

[33] Y. Shakeel, Dijkstra's Algorithm Level 2 of 2 - step by step guide, 2014. 
[34] I. Altanis, S. Retalis and O. Petropoulou, "Systematic Design and Rapid Development of Motion-Based Touchless Games for Enhancing Students' Thinking Skills," Education Sciences, vol. 8, no. 1, pp. 1-15, 2018.

[35] W. Chen and A. Tat Yao, "An Empirical Evaluation of Critical Factors Influencing Learner Satisfaction in Blended Learning: A Pilot Study," Universal Journal of Educational Research, vol. 4, no. 7, pp. 1667-1671, 2016.

[36] N. Flack, et al., "Leveraging Serious Games in Air Force Multi-Domain Operations Education: A Pilot Study," in ICCWS 2020 15th International Conference on Cyber Warfare and Security, Norfolk, pp. 155-164, 2020.

[37] P. Dawson and W. Sutherland-Smith, "Can markers detect contract cheating? Results from a pilot study," Assessment \& Evaluation in Higher Education, vol. 43, no. 2, pp. 286-293, 2017.

[38] J. Aspelin and A. Jonsson, "Relational competence in teacher education. Concept analysis and report from a pilot study," Teacher Development, vol. 23, no. 2, pp. 264-283, 2019.

[39] A. Beltrán-Velasco, et al., "The Effect of Cultural Differences in Psychophysiological Stress Response in High Education Context: A Pilot Study," Applied Psychophysiology and Biofeedback, vol. 45, no. 1, pp. 23-29, 2019.

[40] J. Baker, P. Moyer-Packenham, S. Tucker, J. Shumway, K. Jordan and R. Gillam, "The Brain's Response to Digital Math Apps: A Pilot Study Examining Children's Cortical Responses During Touch-Screen Interactions," Journal of Computers in Mathematics and Science Teaching, vol. 37, no. 1, pp. 69-86, 2018.

[41] P. Cummings, Analysis of Incidence Rates. Boca Raton: CRC Press, 2019.

[42] M. Shoukri, Analysis of Correlated Data with SAS and R, 4th ed. Milton: CRC Press, 2018.

[43] D. Dicheva and A. Hodge, "Active Learning through Game Play in a Data Structures Course," in 49th ACM Technical Symposium on Computer Science Education (SIGCSE '18), Maryland, pp. 834-839, 2018.

[44] V. Kannappan, et al., "La Petite Fee Cosmo: Learning Data Structures Through Game-Based Learning," in 2019 International Conference on Cyberworlds (CW), Kyoto, Vol. 1, pp. 207-210, 2019.

[45] J. Hamari, D. Shernoff, E. Rowe, B. Coller, J. Asbell-Clarke and T. Edwards, "Challenging games help students learn: An empirical study on engagement, flow and immersion in game-based learning," Computers in Human Behavior, vol. 54, pp. 170-179, 2016. [Online]. Available: 10.1016/j.chb.2015.07.045

[46] F. Ke, K. Xie and Y. Xie, "Game-based learning engagement: A theory- and data-driven exploration," British Journal of Educational Technology, vol. 47, no. 6, pp. 1183-1201, 2015. [Online]. Available: 10.1111/bjet.12314

[47] M. Shahid, A. Wajid, K. Ul Haq, I. Saleem and A. Shujja, "A Review of Gamification for Learning Programming Fundamental," in 2019 International Conference on Innovative Computing (ICIC), Lahore, pp. 1-8, 2019. 